\title{
Fatty acid profile and health lipid indices in the raw milk of Simmental and Holstein-Friesian cows from an organic farm
}

\author{
R. Pilarczyk ${ }^{\#}$, J. Wójcik, P. Sablik \& P. Czerniak \\ Department of Ruminant Science, West Pomeranian University of Technology in Szczecin, Judyma 10 Street, \\ 71-460 Szczecin, Poland
}

(Received 23 June 2014; Accepted 2 January 2015; First published online 26 February 2015)

\begin{abstract}
Copyright resides with the authors in terms of the Creative Commons Attribution 2.5 South African Licence.
See: http://creativecommons.org/licenses/by/2.5/za

Condition of use: The user may copy, distribute, transmit and adapt the work, but must recognise the authors and the South African Journal of Animal Science.
\end{abstract}

\begin{abstract}
The aim of this study was to compare the health-related fatty acid (FA) profiles and health lipid indices in the raw milk of Simmental and Holstein-Friesian cows from an organic farm. The milk from Simmental cows had a significantly higher content of C12:0, C16:1cis9, C17:1trans9, C18:2cis9,12 (LA), C18:3cis9,12,15 (LNA), C20:1cis9, C20:4cis5,8,11,14, n-6 PUFA, total polyunsaturated fatty acids (PUFAs) and unsaturated fatty acids (UFAs), and a lower content of C15:0, C18:0, C20:0, C22:0 and conjugated linoleic acid (CLA) in the total content of FA than the milk of Holstein-Friesian cows. The PUFA/SFA and UFA/saturated fatty acid (SFA) ratios in the milk from Simmental cows were significantly higher, whereas the thrombogenic index and the LA/LNA ratio were significantly lower compared with the milk of HolsteinFriesian cows.
\end{abstract}

Keywords: Atherogenic index, bovine milk, cows, breeds, SFA, PUFA, CLA, thrombogenic index

\#Corresponding author: Renata.Pilarczyk@zut.edu.pl

\section{Introduction}

Bovine milk is recognized as an important source of energy, high-quality protein and essential minerals and vitamins. However, several studies report negative effects on human health from the consumption of bovine milk. Results from those studies have led to an ongoing debate on the role of milk and dairy products in human health (Lock \& Bauman, 2004; Palmquist et al., 2006; Maurice-Van Eijndhoven et al., 2011). Owing to the negative effects of some saturated fatty acids (SFAs) on human health, milk fat has a bad reputation, because it is composed of 65\% - 75\% SFA (Arnould \& Soyeurt, 2009).

The proportions of each fatty acid (FA) that is produced determine the lipid fraction's health impact (Muchenje et al., 2009; Palladino et al., 2010; Nantapo et al., 2014). Recent studies have linked the whole lipid content to the emergence of chronic disorders such as diabetes and cardiovascular diseases (Williams, 2000). However, extensive modern research on the effect of FAs on human health indicates that only a few individual FAs are responsible for the negative consequences on consumer health (Simopoulos, 2002). Diets rich in FAs, such as lauric (C12:0), myristic (C14:0) and palmitic acids (C16:0), are highly related to an increased risk of atherosclerosis, obesity and coronary heart diseases (Ulbricht \& Southgate, 1991; Haug et al., 2007; Arnould \& Soyeurt, 2009). The unsaturated fatty acids (UFAs) are usually called 'healthy fats', especially for their impact on the level of cholesterol in blood (Haug et al., 2007; Arnould \& Soyeurt, 2009). Milk contains a low concentration of beneficial UFAs, including conjugated linoleic acid (CLA) (C18:2cis9trans11), $\alpha$-linolenic (LNA, 18:3n-3) and oleic acids (C18:1cis9), which could be improved in milk through pasture feeding (Simopoulos, 2002; Nantapo et al., 2014). The potential benefits of CLA include the lowering of blood total (low-density lipoprotein and high-density lipoprotein) cholesterol content, anticarcinogenic, antidiabetic and immunomodulation effects (Mills et al., 2011). Benefits of $n-3$ FA include prevention of heart disease and improved immune response (Muchenje et al., 2009). Polyunsaturated fatty acids (PUFAs) decrease cholesterol content more strongly than monounsaturated fatty acids (MUFAs) (Williams, 2000). Oleic acid (C18:1cis9) and linolenic acid (C18:3cis9,12,15), which belong to the $n-3$ family, have anticancer and antiatherogenic properties (Williams, 2000; Haug et al., 2007). Besides its effect on 
cholesterol level, linoleic acid $(\mathrm{C} 18: 2$ cis9,12), the most important in the $n-6$ family, improves sensitivity to insulin and thus reduces the incidence of type 2 diabetes (Arnould \& Soyeurt, 2009).

The FA profile of dairy fat is important for the nutritional quality of dairy products. The ratios of unsaturated fatty acids PUFA/SFA, $n-6 / n-3$ PUFA, hypocholesterolaemic/hypercholesterolaemic $(\mathrm{h} / \mathrm{H})$, atherogenic and thrombogenic indexes are widely used to evaluate the nutritional value of milk fat.

Cow milk FA composition is linked to intrinsic (stage of lactation, pregnancy, breed or genotype) or extrinsic (nutrition, season, temperature) factors. The diet used in the herd plays a central role in determining the variation in milk fat composition. Also, a significant part of the variability in FA composition is genetically determined (Beaulieu \& Palmquist, 1995; Stoop et al., 2008; Maurice-Van Eijndhoven et al., 2011). More recently, researchers have addressed again the issue of breed and genotypic effects on milk FA composition (Drackley et al., 2001; Carroll et al., 2006; Palladino et al., 2010; Maurice-Van Eijndhoven et al., 2011; Nantapo et al., 2014), in part because of the concern regarding human consumption of saturated lipid in dairy products and their association with cardiovascular disease (Lichtenstein, 2003).

Differences between breeds from several independent investigations are ambiguous for most of the FA profiles (Samková et al., 2012). Two breeds, Holstein (Friesian) and Jersey, have been tested most frequently (Morales et al., 2000; White et al., 2001; Palladino et al., 2010; Nantapo et al., 2014). Nevertheless, inter-breed differences in the milk fat composition were reported in other breeds, such as Brown Swiss, Montbéliarde, Belgian Blue, Tarentaise, Normande and Swedish Red (Lawless et al., 1999; Kelsey et al., 2003; Soyeurt et al., 2006; Ferlay et al., 2006; Poulsen et al., 2012), particularly in comparison with the Holstein. However, little information is available on the comparison between Holstein and Simmental cows (Barłowska et al., 2009). In addition, most breed comparison studies have been carried out under total mixed ration (TMR) systems or with grazing animals receiving supplements (Morales et al., 2000; Kliem et al., 2009; Ferlay et al., 2010; Kuczyńska et al., 2012). Only a few studies have evaluated the FA profiles and nutritional quality of milk of different breeds grazing pastures (Lawless et al., 1999; White et al., 2001; Nantapo et al., 2014). Therefore, the aim of this study was to compare the health-related FA profile and health lipid indices in the raw milk of Simmental and Holstein-Friesian cows from an organic farm.

\section{Material and Methods}

Individual milk samples were collected from 20 Simmental dairy cows and 20 Holstein-Friesian (HF) cows kept on an organic farm with a total area of 4000 ha of arable land, including 3000 ha of grassland, located in the northwestern part of the Lubuskie Province, Poland. Approximately 1000 ha is located in the Mouth of Warta National Park. The remaining area is part of Natura 2000 land. Grasslands are situated in the basin of Odra and Warta Rivers. This farm, which specializes in milk production, is the only one in this area that maintains HF and Simmental cows under the same conditions, grazing them in the national park and its buffer zone.

The animals were kept in a loose barn with free access to a stockyard located along the long walls of the building. Winter feeding of cows was based on preserved feeds obtained from the farm (maize silage, wilted silage, ensilaged sugar beet pulp, hay and concentrates), whereas during the summer, cows used the pasture additionally.

For each cow, $50 \mathrm{~mL}$ of milk were collected once in September 2008. The cows were grazed on pasture in this period. Each group, within the evaluated breed, consisted of cows of similar milk yield (3 $800-4000 \mathrm{~kg}$ ), similar age (3 - 7 years old) and similar lactation stage (100 - 150 days post calving). The cows within each breed were sired by many bulls from different families (15 and 14 for the HF and Simmental breeds, respectively).

The FA content was determined with reversed-phase high-pressure liquid chromatography (HPLCRPC), according to Osterroht (1987) using the Äkta Purifier apparatus (Pharmacia Biotech) with a UV-VIS detector (range $190-700 \mathrm{~nm}$ ). Chromatographic separations were performed on a LiChroCart (TM) HPLC 250-4 Superspher (TM) 60 RP-8 $(4 \mu \mathrm{m})$ column and a LiChroCART ${ }^{\circledR} 4-4$ LiChrospher 100 RP-8 $(5 \mu \mathrm{m})$ precolumn (Merck). Single FA standards (Sigma) were used for peak identification. Unicorn 2.30 software was used for peak integration. The milk samples to determine FA content were prepared in compliance with AOAC 969.33.2000 and AOAC 963.22.2000 (AOAC, 2000).

Statistical analysis of the data was performed using Statistica software (StatSoft Inc., version 10.0). Prior to analyses, data were investigated to determine their distribution using the Shapiro-Wilk W test. The FA contents were log transformed to attain or approach a normal distribution of the data. The content of the analysed FAs and health lipid indices in cow's milk were compared with Student's t-test between Simmental and HF breeds. Differences were considered statistically significant at the levels of $P<0.05, P<0.01$ and $P$ $<0.001$. All data are expressed throughout the text as arithmetic means, minimum and maximum values as well as standard errors of the mean (SEM). 


\section{Results and Discussion}

An analysis of the percentage content of individual FAs (Table 1) showed that the milk from Simmental cows had a significantly $(P<0.05)$ higher content of C12:0, C16:1cis9, C17:1trans9, C18:2cis9,12 (LA), C18:3cis9,12,15 (LNA), C20:1cis9, C20:4cis5,8,11,14, n-6 PUFA, total PUFAs and UFAs, and a lower content of C15:0, C18:0, C20:0, C22:0 and CLA in the total content of fatty acids compared with the milk of HF cows.

A comparison of milk FA levels between Holstein and Simmental cows has rarely been done. Only Barłowska et al. (2009) compared the content of FAs in the milk of Simmental and HF cows. Similarly to the present study, the Simmental milk was characterized by a significantly lower concentration of CLA and total SFA, and a higher concentration of PUFA and UFA in comparison with HF cows. Previous studies (Barłowska et al., 2005; 2006) demonstrated that the milk of Polish Holstein-Friesian (PHF) Black-and-White and Red-and-White cows had a lower level of CLA compared with the milk of Simmental cows. However, it should be emphasized that, in these studies, the cows of the above-mentioned breeds were kept on separate farms.

Milk FA concentration has been compared in many other cattle breeds, including local ones. Differences in the FA composition have been reported in the milk of HF and Jersey cows (Beaulieu \& Palmquist,1995; Drackey et al., 2001; White et al., 2001; Kliem et al., 2009; Palladino et al., 2010; Nantapo et al., 2014), Holstein and Brown Swiss cows (Kelsey et al., 2003; Moore et al., 2005; Kuczyńska et al., 2011), Holstein, Jersey and Brown Swiss cows (DePeters et al., 1995; Carroll et al., 2006), Holstein and Czech Pied cows (Pešek et al., 2005), Tarentaise and Montbéliarde cows (Ferlay et al., 2006), Montbéliarde, Irish Holstein/Friesian, Dutch Holstein/Friesian, and Normande cows (Lawless et al., 1999), Danish Holstein, Danish Jersey and Swedish Red cows (Poulsen et al., 2012), as well as HF, Meuse-Rhine-Yssel, Dutch Friesian, Groningen White Headed and Jersey cows (Maurice-Van Eijndhoven et al., 2013).

Holstein and Jersey milk fats presented the greatest differences. Higher concentrations of SFAs, especially those of FAs with short and medium carbon chains (C4:0 to C16:0), were observed in Jersey milk fat (Beaulieu \& Palmquist 1995; White et al., 2001; Carroll et al., 2006). DePeters et al. (1995) reported that the milk fat of Jerseys tended to have higher proportions of C6:0 and C8:0 than that of Holsteins and higher proportions of $\mathrm{C} 10: 0$ and $\mathrm{C} 12: 0$ than that of Holsteins and Brown Swiss. The concentration of Cl4:0, C16:0, and C18:2 did not differ among breeds, but C18:3 was lowest in milk from Brown Swiss cows. Milk fat of Jerseys had the highest concentration of C18:0 and the lowest concentration of C18:1. Some studies have shown a higher concentration of 16:0 for milk from Jersey than from Holstein cows (Drackey et al., 2001, Palladino et al., 2010), but others reported opposite results (White et al., 2001). According to Lawless et al. (1999), Normande and Montbéliarde cows produce milk fat with the highest proportions of C18:0. In the study by Ferlay et al. (2006), milk fat from Tarentaise cows contained a lower proportion of C16:0 and a higher proportion of C18:0 than that from Montbéliarde cows. In the study by Carroll et al. (2006), Brown Swiss cows had higher proportions of many monounsaturated trans FA in milk fat compared with Jersey and Holstein cows, and breed had no effect on the C18:0, C18:2, C18:2cis9trans11 and C18:3 concentrations. The FA content has also been compared in the milk from Montbéliarde and HF cows. In the study by Kuczyńska et al. (2012), the milk from Montbéliarde cows was characterized by a significantly higher level of C14:0, C18:0, 18:2cis9trans11 and total SFA, and significantly lower level of C18:2trans10cis12, C20:3n-6 and C22:6n-3 than the milk of the HF breed. Similar results were obtained in the study by Ferlay et al. (2010), in which Holstein cows had lower percentages of total SFA and higher of total monounsaturated fatty acids (MUFA) and PUFA concentration, though higher percentages of CLAcis9trans11, than from Montbéliarde cows.

Mele et al. (2007) and Schennink et al. (2008) attributed differences in milk fat composition among breeds to varying activity of Delta ${ }^{9}$-desaturase (Samková et al., 2012). $\Delta^{9}$-desaturase, also named stearoyl coenzyme-A desaturase (SCD), catalyses the introduction of a cis-double bond between carbons 9 and 10 of SFA with a chain length of $10-18$ carbons. Therefore, it converts specific medium- and long-chain SFA into the corresponding MUFA (Reh et al., 2004). This last activity is an essential step in the synthesis of unsaturated FA. SCD oxidizes C16:0 and C18:0 to C16:1 and C18:1 and is involved in the CLA production (Dhiman et al., 2005). Up to 90\% of the CLA in bovine milk is formed because of the activity of this enzyme in the mammary gland (Arnould \& Soyeurt, 2009).

Previous studies have shown differences in the activity of the $\Delta 9$-desaturase enzyme between breeds and between animals within breed (Kelsey et al., 2003; Soyeurt et al., 2008). Mammary $\Delta^{9}$-desaturase activity is thought to be lower in the Jersey compared with Holstein and Brown Swiss cows (Beaulieu \& Palmquist, 1995; DePeters et al., 1995; Drackley et al., 2001), which would contribute to a greater proportion of saturated fatty acids in milk from the Jerseys. Differences in $\Delta^{9}$-desaturase activities also offer a plausible explanation for the lower concentration of certain cis-MUFA in Jersey milk (Kliem et al., 
Table 1 Fatty acid profile (\% of total fatty acids) in milk of Holstein-Friesian and Simmental breeds

\begin{tabular}{|c|c|c|c|c|c|c|c|c|c|}
\hline \multirow{2}{*}{ Parameter } & \multicolumn{4}{|c|}{ Holstein-Friesian } & \multicolumn{4}{|c|}{ Simmental } & \multirow{2}{*}{$P$ value } \\
\hline & Mean & Min. & Max. & SEM & Mean & Min. & Max. & SEM & \\
\hline C12:0 & 3.24 & 2.99 & 3.56 & 0.044 & 3.44 & 2.99 & 3.93 & 0.068 & $0.022^{*}$ \\
\hline C13:0 & 0.13 & 0.12 & 0.15 & 0.002 & 0.13 & 0.12 & 0.15 & 0.002 & 0.104 \\
\hline C14:0 & 12.23 & 11.70 & 12.60 & 0.051 & 12.32 & 11.80 & 12.90 & 0.072 & 0.313 \\
\hline C15:0 & 1.93 & 1.73 & 2.16 & 0.031 & 1.79 & 1.63 & 1.99 & 0.026 & $0.002^{\star \star}$ \\
\hline C16:0 & 33.05 & 32.40 & 33.50 & 0.069 & 32.97 & 32.60 & 33.30 & 0.045 & 0.307 \\
\hline C16:1cis9 & 1.72 & 1.47 & 1.88 & 0.028 & 1.89 & 1.74 & 2.13 & 0.024 & $<0.001^{\star \star \star}$ \\
\hline C17:0 & 1.33 & 1.05 & 1.60 & 0.037 & 1.29 & 0.99 & 1.57 & 0.041 & 0.389 \\
\hline C17:1trans9 & 0.013 & 0.01 & 0.01 & 0.006 & 0.014 & 0.01 & 0.01 & 0.000 & $<0.001^{\star \star \star}$ \\
\hline C18:0 & 13.31 & 13.10 & 13.60 & 0.030 & 13.04 & 12.60 & 13.40 & 0.046 & $<0.001^{\star \star \star}$ \\
\hline C18:1cis9 & 27.51 & 26.80 & 28.30 & 0.106 & 27.40 & 26.40 & 28.20 & 0.108 & 0.471 \\
\hline C18:2cis9,12 n-6 (LA) & 2.74 & 2.61 & 2.92 & 0.019 & 2.90 & 2.73 & 3.07 & 0.026 & $<0.001^{\star \star *}$ \\
\hline CLA & 0.85 & 0.54 & 1.03 & 0.029 & 0.77 & 0.51 & 0.90 & 0.020 & $0.029^{*}$ \\
\hline C18:3cis9,12,15 n-3 (LNA) & 0.94 & 0.81 & 1.05 & 0.017 & 1.08 & 0.93 & 1.19 & 0.019 & $<0.001^{\star \star \star}$ \\
\hline C20:0 & 0.28 & 0.27 & 0.30 & 0.002 & 0.27 & 0.25 & 0.28 & 0.002 & $<0.001^{\star \star \star}$ \\
\hline C20:1cis 9 & 0.32 & 0.29 & 0.34 & 0.003 & 0.35 & 0.32 & 0.37 & 0.003 & $<0.001^{\star \star \star}$ \\
\hline C20:2cis $11,14 n-6$ & 0.04 & 0.03 & 0.04 & 0.000 & 0.04 & 0.03 & 0.04 & 0.000 & 0.428 \\
\hline C20:3cis8,11,14 n-6 & 0.08 & 0.07 & 0.09 & 0.002 & 0.08 & 0.07 & 0.09 & 0.001 & 0.322 \\
\hline C20:4cis5,8,11,14 n-6 & 0.139 & 0.13 & 0.14 & 0.001 & 0.144 & 0.14 & 0.15 & 0.001 & $<0.001^{\star \star \star}$ \\
\hline $\mathrm{C} 22: 0$ & 0.163 & 0.14 & 0.18 & 0.004 & 0.158 & 0.12 & 0.17 & 0.004 & $0.013^{\star}$ \\
\hline SFA & 65.67 & 64.97 & 66.70 & 0.097 & 65.38 & 64.71 & 66.45 & 0.113 & 0.065 \\
\hline MUFA & 29.56 & 28.93 & 30.36 & 0.097 & 29.66 & 28.67 & 30.38 & 0.107 & 0.520 \\
\hline PUFA & 4.78 & 4.32 & 5.18 & 0.049 & 5.01 & 4.62 & 5.24 & 0.041 & $0.001^{\star \star \star}$ \\
\hline$n-3$ PUFA & 1.79 & 1.35 & 2.06 & 0.039 & 1.85 & 1.60 & 2.09 & 0.028 & 0.223 \\
\hline$n-6$ PUFA & 3.00 & 2.86 & 3.19 & 0.019 & 3.16 & 2.98 & 3.34 & 0.026 & $<0.001^{\star \star \star}$ \\
\hline UFA & 34.34 & 33.65 & 35.13 & 0.099 & 34.66 & 33.55 & 35.46 & 0.116 & $0.043^{\star}$ \\
\hline DFA & 47.65 & 46.96 & 48.53 & 0.099 & 47.70 & 46.35 & 48.46 & 0.120 & 0.727 \\
\hline HFA & 48.52 & 47.82 & 49.25 & 0.085 & 48.72 & 48.24 & 49.86 & 0.095 & 0.126 \\
\hline DI (18) & 67.40 & 66.50 & 68.36 & 0.107 & 67.75 & 66.67 & 68.81 & 0.125 & $0.038^{\star}$ \\
\hline DI (16) & 4.94 & 4.34 & 5.32 & 0.074 & 5.43 & 5.02 & 6.06 & 0.068 & $<0.001^{\star \star *}$ \\
\hline
\end{tabular}

SFA: total saturated fatty acid; MUFA: total monounsaturated fatty acids; PUFA: total polyunsaturated fatty acids; UFA: total unsaturated fatty acid (MUFA+PUFA); $n-6$ PUFA: total $n-6$ PUFA fatty acids; $n-3$ PUFA: total $n-3$ PUFA fatty acids; DFA: desirable fatty acids= UFA + C18:0; HFA: hypercholesterolaemic FA (sum of C12:0, C14:0, and C16:0); DI (18): $\Delta^{9}$-desaturase (18) index = 100(18:1/(18:1+18:0)); DI (16): $\Delta^{9}$-desaturase $(16)$ index = 100(16:1/(16:1+16:0))

2009). White et al. (2001) reported the lower proportions of cis-9 C16:1 and C18:1cis9 for Jersey compared with HF. For C18:1cis9, Beaulieu \& Palmquist (1995) and Palladino et al. (2010) also found lower proportions for Jersey compared with HF. Soyeurt et al. $(2006 ; 2008)$ observed that the milk fat produced by dual-purpose Belgian Blue cows had the highest concentration of unsaturated FA. The observed breed differences were partly explained by the values of indices such as C14:1cis9/C14:0, C16:1cis9/C16:0 and C18:1/C18:0, reflecting the activity of $\Delta^{9}$-desaturase (Samková et al., 2012). In the present study, the values of both $\Delta^{9}$-desaturase $(16)$ and $(18)$ indices in the milk from Simmental cows were significantly $(P<0.05)$ higher, which could indicate a higher desaturase activity compared with HF cows (Table 1). This is a plausible explanation for the higher proportions of C16:1cis9 and lower ones of C18:0 in Simmental milk.

According to Arnould \& Soyeurt (2009), the presence of some single nucleotide polymorphisms could partly explain the observed individual genetic variability. The polymorphisms detected in the SCD1 and 
DGAT1 genes influence the milk FA composition. The SCD1 $\vee$ allele increases the unsaturation of C16:0 and C18:0, whereas the DGAT1 A allele is related to the unsaturation of C18:0.

The PUFA/SFA and n-6/n-3 PUFA ratios, atherogenity index (Al) and thrombogenity index (TI) are commonly used to assess the nutritional value and consumer health of intramuscular fat. In general, a ratio of PUFA to SFA above about 0.45 and a ratio of $n-6 / n-3$ below 4.0 are required in the diet to combat 'lifestyle diseases' such as coronary heart disease and cancers (Simopoulos, 2002). In the present study, the PUFA/SFA ratios $(0.07-0.08)$ were considerably lower than the recommended values, whereas the $n-6 / n-3$ ratios (1.69 - 1.72) were within the recommended levels. The PUFA/SFA and UFA/SFA ratios in the milk from Simmental cows were significantly $(P<0.05)$ higher compared with the milk of HF cows (Table 2$)$. Barłowska et al. (2009) also reported that the milk of Simmental cows was characterized by the most beneficial SFA/UFA (1.81), MUFA/SFA (0.52) and PUFA/SFA (0.05) ratios compared with the milk of HF cows. PUFA/SFA ratios similar to those in the present study (0.06) were also reported by Kuczyńska et al. (2012) in the milk of Montbéliarde and PHF cows fed a TMR. A low PUFA/SFA ratio (0.02 - 0.04) in the milk of Friesian, Jersey and Friesian $x$ Jersey cows under a pasture-based dairy system was also indicated by Nantapo et al. (2014).

A low PUFAISFA ratio in this study resulted from a high content of some SFA in the milk of the investigated breeds, especially that of palmitic (C16:0), stearic (C18:0) and myristic (C14:0) acids, whose consequence was a very high total content of SFA, amounting to above 65\%. Barłowska et al. (2006; 2009) reported a lower content of SFA in Simmental milk (61\%) and a higher one in PHF milk (68\%) compared with that in the present study, while Kuczyńska et al. (2012) found a lower total content of SFA in the milk of PHF cows (62\%). In most previous studies, the mean total proportion of SFA in the milk of Holstein cows ranged from 58\% to 74\% (Pešek et al., 2005; Ferlay et al., 2006; 2010; Kuczyńska et al., 2011; Maurice-Van Eijndhoven et al., 2011).

The mean content of predominant SFAs such as C16:0, C18:0 and C14:0 obtained in these studies was similar to or slightly lower than that in the present work. However, a markedly lower content of stearic acid was noted in some studies. Pešek et al. (2005), Kliem et al. (2009), Ferlay et al. (2010) and MauriceVan Eijndhoven et al. (2011) even determined a higher proportion of myristic acid than stearic acid in the milk of Holstein cows.

However, some authors considered that an index such as PUFA/SFA may not be an adequate way to evaluate the nutritional value of fat because some SFAs do not increase plasma cholesterol and ignore the effects of MUFA (Orellana et al., 2009). SFAs constitute the primary fat component of the human diet. An excessively high proportion of SFA in the diet may cause chronic diseases such as atherosclerosis, heart failure or obesity. General dietary recommendations concerning the reduction of SFA and cholesterol consumption have contributed to an erroneous belief that dairy products, particularly full-fat, may lead to coronary heart disease (German et al., 2009). The studies conducted since 2000 have contradicted the

Table 2 Health lipid indices in milk of Holstein-Friesian and Simmental breeds

\begin{tabular}{|c|c|c|c|c|c|c|c|c|c|}
\hline \multirow{2}{*}{ Parameter } & \multicolumn{4}{|c|}{ Holstein-Friesian } & \multicolumn{4}{|c|}{ Simmental } & \multirow{2}{*}{$P$ value } \\
\hline & Mean & Min. & Max. & SEM & Mean & Min. & Max. & SEM & \\
\hline PUFA/SFA & 0.07 & 0.07 & 0.08 & 0.001 & 0.08 & 0.07 & 0.08 & 0.001 & $0.001^{\star \star \star}$ \\
\hline MUFA/SFA & 0.45 & 0.44 & 0.47 & 0.002 & 0.45 & 0.43 & 0.47 & 0.002 & 0.279 \\
\hline UFA/SFA & 0.52 & 0.50 & 0.54 & 0.002 & 0.53 & 0.50 & 0.55 & 0.003 & $0.043^{*}$ \\
\hline n6/n3 PUFA & 1.69 & 1.48 & 2.19 & 0.039 & 1.72 & 1.46 & 1.93 & 0.027 & 0.575 \\
\hline HFA/UFA & 1.41 & 1.36 & 1.46 & 0.006 & 1.41 & 1.36 & 1.49 & 0.007 & 0.455 \\
\hline $\mathrm{Al}$ & 2.48 & 2.38 & 2.55 & 0.012 & 2.47 & 2.37 & 2.64 & 0.016 & 0.653 \\
\hline $\mathrm{TI}$ & 2.32 & 2.24 & 2.42 & 0.012 & 2.28 & 2.21 & 2.39 & 0.011 & $0.011^{*}$ \\
\hline$h / H$ & 0.61 & 0.58 & 0.64 & 0.003 & 0.61 & 0.57 & 0.63 & 0.003 & 0.446 \\
\hline LA/LNA & 2.94 & 2.52 & 3.36 & 0.049 & 2.71 & 2.32 & 3.13 & 0.052 & $0.002^{\star *}$ \\
\hline
\end{tabular}

SFA: saturated fatty acids; MUFA: monounsaturated fatty acids; PUFA: polyunsaturated fatty acid;

HFA: hypercholesterolaemic fatty acid; IA: index of atherogenity $=(12: 0+4 \times 14: 0+16: 0) /($ MUFA + PUFA $)$ calculated according to Ulbricht \& Southgate (1991); IT: index of thrombogenity= $(12: 0+16: 0+18: 0) /[(0.5 \times M U F A)+(0.5 \times n-6$ PUFA $)+(3 \times$ n-3 PUFA $)+(n-3$ PUFAn-6 PUFA)] calculated according to Ulbricht \& Southgate (1991);

$\mathrm{h} / \mathrm{H}$ : hypocholesterolemic/hypercholesterolemic ratio $=(\mathrm{C} 18: 1+\mathrm{PUFA}) /(\mathrm{C} 14: 0+\mathrm{C} 16: 0)$. 
thesis that the consumption of milk and dairy products would increase the synthesis of LDL and the risk of coronary disease. At present, it is believed that the increased LDL blood concentration is attributable to lauric (C12:0), myristic (C14:0) and palmitic (C16:0) acids, while the other SFAs found in milk neutralize their effect since they increase HDL level (Parodi, 2009; Markiewicz-Kęszycka et al., 2013). In addition, it has been shown that the $\mathrm{C} 14: 0$ has the potential to increase cholesterol concentrations 4 to 6 times greater than C16:0 (Mensink \& Katan, 1992).

In the present study, the predominant FAs were C16:0, C18:1cis9, C18:0 and C14:0. The high levels of C16:0 and C14:0 in the current study are not desirable, although this is partly countered by the contents of MUFA, in particular oleic acid, and PUFA. MUFAs have a positive effect on the concentration of high density lipoproteins (HDL), transporting cholesterol from blood vessel walls to the liver, where it is degraded by bile acids, which are afterwards excreted from the organism. At the same time, MUFAs reduce the concentration of low density lipoproteins (LDL), which are deposited in blood vessels when circulating over the entire organism (Markiewicz-Kęszycka et al., 2013). Oleic acid increases the concentration of HDL-cholesterol and lowers the concentration of LDL. In most previous studies, the mean proportion of oleic acid (C18:1cis9) in the milk of Holstein cows was lower than in present study and ranged from 21.6\% to 25\% (White et al., 2001; Kelsey et al., 2003; Pešek et al., 2005; Kliem et al., 2009; Kuczyńska et al., 2012).

In the PUFA category, C18:2cis9,12 (LA) and C18:3cis9,12,15 (LNA) predominated in both breeds. Barłowska et al. (2006; 2009) reported a lower content of PUFA in Simmental and PHF milk (3.62\% - 4\% and $2.78 \%-2.84 \%$, respectively) compared with that in the present study. In previous studies, the mean total proportion of PUFA in the milk of Holstein cows was lower and ranged from 2.8\% to 4.9\% (White et al., 2001; Kelsey et al., 2003; Kliem et al., 2009; Ferlay et al., 2010; Kuczyńska et al., 2012). Long-chain PUFAs are beneficial to human health owing to their antitherogenic, antithrombotic and anti-inflammatory effects (Williams, 2000).

The nutritional value of milk is related to essential FAs, such as linoleic (LA) and $\alpha$-linolenic acid (LNA), as well as specific FAs showing beneficial health effects, such as CLA and $n-3$ PUFA (Poulsen et al., 2012). C18:3cis9,12,15 (LNA) and C18:2 cis9,12 (LA) are two essential FAs in the human diet and arise in bovine milk directly from the cow's diet, together comprising the main fraction of the $n-3$ and $n-6$ groups, respectively (Maurice-van Eijndhoven et al., 2013). Consumption of $n-3$ PUFA and CLA, especially the cis9trans11 isomer, has been associated with putative positive effects on human health. The $n-3$ PUFA are widely recommended for preventing heart disease, whereas CLA has beneficial effects on human health as a result of its anticarcinogenic, antiatherogenic, antidiabetic and antiadipogenic properties (Parodi, 1999; Palladino et al., 2010). Milk fat is the main dietary source of CLA (Mills et al., 2011).

In the present study, the milk from Simmental cows had a significantly $(P<0.001)$ higher percentage of LA and LNA in the total content of fatty acids, whereas the milk from HF cows had a significantly $(P<0.05)$ higher percentage of CLA. The significantly higher production of LA for HF cows compared with Jerseys was reported by Palladino et al. (2010) and Nantapo et al. (2014), while Kelsey et al. (2003) observed the difference between HFs and Brown Swiss. In contrast, Kliem et al. (2009) found that Jersey cows had more LA concentrations in milk than Holsteins. Drackley et al. (2001) reported the significantly higher proportions of LNA compared with Jersey cows, while Ferlay et al. (2010) and Kuczyńska et al. (2012) noted increased proportions compared with Montbéliarde cows. However, the differences between breeds for LA and LNA have not been found in many studies (Beaulieu \& Palmquist, 1995; Morales et al., 2000; White et al., 2002; Moore et al., 2005). In the present study, the LA/LNA ratio in the milk from Simmental cows was significantly $(P<0.05)$ lower compared with the milk of HF cows, which indicates a more favourable proportion of these acids in the milk from the former breed (Table 2).

In the study by Barłowska et al. (2009), as in the present study, HF milk was characterized by a significantly higher content of CLA in comparison with Simmental milk. However, previous studies (Barłowska et al., 2005; 2006) demonstrated that the milk of PHF cows had a lower level of CLA compared with the milk of Simmental cows. These studies also showed that the CLA content in milk differed between breeds. In the study by Lawless et al. (1999), Montbéliarde cows displayed a tendency to have a higher CLA concentration in milk fat compared with HF or Normande cows grazing on pasture. In contrast, Kliem et al. (2009) and Kuczyńska et al. (2012) found that Holstein cows had more CLA in milk than Montbéliarde cows fed a maize-silage-based diet or a TMR, respectively. HF cows had a higher CLA concentration in milk compared with Jerseys fed diets containing conserved forages and grains (Morales et al., 2000; Dhiman et al., 2005) or grazing on pasture (White et al., 2002). Brown Swiss cows had a higher CLA concentration in milk fat than HF cows when fed similar diets (Moore et al., 2005). However, Kelsey et al. (2002) found that HF and Brown Swiss cows fed diets containing conserved forages and grain produced milk fat with a similar CLA concentration (Dhiman et al., 2005).

In most previous studies, the mean proportion of LNA and CLA in the milk of Holstein cows was lower than that in the present study and ranged from 0.3\% to 0.8\% (Beaulieu \& Palmquist, 1995; Drackley et al., 
2001; White et al., 2001; Kelsey et al., 2003; Pešek et al., 2005; Carroll et al., 2006; Ferlay et al., 2006; Ferlay et al., 2010; Kuczyńska et al., 2012). In the study by Barłowska et al. (2009), the mean percentage content of CLA in the milk of Simmental cows was also lower and ranged from $0.51 \%$ to $0.73 \%$ (Barłowska et al., 2006; 2009).

In an attempt to consider the different effects of the various FA, Ulbricht \& Southgate (1991) proposed two indices that might better characterize the atherogenic and thrombogenic potential of the diet than simple approaches such as PUFA/SFA ratio. The atherogenic index (AI) and thrombogenic index (TI) take into account the different effects that single FAs might have on the human health and, in particular, on the probability of increasing the incidence of pathogenic phenomena, such as atheroma and/or thrombus formation. $\mathrm{Al}$ and $\mathrm{TI}$ are highest for most atherogenic and thrombogenic dietary components. In the present study, the $\mathrm{TI}$ in the milk from Simmental cows was significantly $(P<0.05)$ lower compared with the milk of HF cows (Table 2). The atherogenic and thrombogenic indices have rarely been calculated in the milk of various cattle breeds. In the study by Kuczyńska et al. (2012), the milk of PHF breed was characterized by significantly lower $\mathrm{Al}$ and Tls in comparison with Montbéliarde milk. The value of $\mathrm{Al}$ in the milk of Holstein cows was lower (2.08), while TI was higher (2.56) than that in the present study. Much higher values of $\mathrm{Al}$ were reported by Ferlay et al. (2006) in the milk of Tarentaise and Montbéliarde cows (3.14 and 3.43, respectively) and Nantapo et al. (2014) in the milk of Friesian, Jersey and Friesian x Jersey cows (4.08 - 5.13).

The variation in the FA composition in milk can be explained partly by differences in the diets of cows. Many authors have noted a reduction in milk short- and medium-chain fatty acids with an increased fresh pasture supply in the diet (Bargo et al., 2006; Nantapo et al., 2014). Grazed grass generally increases the levels of milk oleic acid, PUFA, especially 18:3n-3 and cis9trans11-CLA, and decreases that of saturated medium-chain FA (Chilliard et al., 2007). However, there is evidence of significant variation between individual animals on the same diet and between cow breeds (White et al., 2001; Kelsey et al., 2003). Most breed comparison studies have been carried out under TMR systems or with grazing animals receiving supplements (Morales et al., 2000; Kliem et al., 2009; Kuczyńska et al., 2012). The differences between breeds from several independent investigations are ambiguous for most of the FA profiles. According to Samková et al. (2012), the reasons for these inter-breed differences may be the low number of cows used in these experiments, resulting in the different responses of cows on different diets. This was confirmed by Ferlay et al. (2006), who observed statistically significant differences in the proportion of certain FAs in three experiments with numerically nearly equal groups of Montbéliarde and Tarentaise cows, as well as by the results of the present work.

Besides diet, a considerable part of the variation has a genetic origin. For instance, Mele et al. (2009) reported heritabilities for individual FA in the milk of Italian Holstein-Friesians (HF) ranging from 0.03 to 0.17 and Stoop et al. (2008) found heritabilities for individual FA in the milk of Dutch HF ranging between 0.22 and 0.71 . This indicates that a considerable part of the variation in the FA composition is owing to genetics (Maurice-van Eijndhoven et al., 2013).

The breed differences in the milk FA composition are generally minor when compared with the effects of dietary manipulation or variations among individual cows (Palmquist et al., 1993). Many authors agree that breed contributes less than $1 \%$ of the variation in milk fatty acids and plays a lesser role than nutrition in improving the overall functional fatty acid profile of milk (Nantapo et al., 2014).

\section{Conclusions}

Simmental and HF cows were kept in the same environment and were fed identically. The present research showed that the FA concentration in milk differed between these breeds. The milk of Simmental cows had a slightly more favourable FA composition compared with the milk of HF cows, since it had a significantly higher content of UFAs, such as C18:2cis9,12 (LA), C18:3cis9,12,15 (LNA), C20:4cis5, 8,11,14 and total PUFA and UFA. The PUFA/SFA, UFA/SFA, LA/LNA ratios and TI in the milk from Simmental cows were also more favourable. However, the milk from HF cows had a significantly higher concentration of CLA and a lower concentration of lauric acid (C12:0).

\section{References}

AOAC, 2000. Official Methods of Analysis (17th ed.). Association of Official Analytical Chemists, Inc., Arlington, Virginia, USA.

Arnould, V.M-R. \& Soyeurt, H., 2009. Genetic variability of milk fatty acids. J. Appl. Genet. 50, 29-39.

Bargo, F., Delahoy, J.E., Schroeder, G.F., Baumgard, L.H. \& Muller, L.D., 2006. Supplementing total mixed rations with pasture increase the content of conjugated linoleic acid in milk. Anim. Feed Sci. Technol. $131,226-240$. 
Barłowska, J., Litwińczuk, Z. \& Topyła, B., 2005. Physical-chemical parameters of milk from different cow breeds in spring-summer feeding period. Med. Weter. 61, 937-939 (in Polish, English abstract).

Barłowska, J., Litwińczuk, Z., Król, J. \& Kędzierska-Matysek, M., 2006. Fatty acid profile and minerals content in milk from cows of various breeds over spring-summer feeding period. Pol. J. Food Nutr. Sci. 56, 13-16.

Barłowska, J., Grodzicki, T., Topyła, B. \& Litwińczuk, Z., 2009. Physicochemical properties of milk fat from three breeds of cows during summer and winter feeding. Arch. Tierz. 52, 356-363.

Beaulieu, A.D. \& Palmquist, D.L., 1995. Differential effects of high fat diets on fatty acid composition in milk of Jersey and Holstein cows. J. Dairy Sci. 78, 1336-1344.

Caroll, S.M., DePeters, E.J., Taylor, S.J., Rosenberg, M., Perez-Monti, H. \& Capps, V.A., 2006. Milk composition of Holstein, Jersey and Brown Swiss cows in response to increasing levels of dietary fat. Anim. Feed Sci. Technol. 131, 451-473.

Chilliard, Y., Glasser, F., Ferlay, A., Bernard, L., Rouel, J. \& Doreau, M., 2007. Diet, rumen biohydrogenation, cow and goat milk fat nutritional quality: a review. Eur. J. Lipid Sci. Technol. 109, 828-855.

DePeters, E.J., Medrano, J.F. \& Reed, B.A., 1995. Fatty acid composition of milk fat from three breeds of dairy cattle. Can. J. Anim. Sci. 75, 267-269.

Dhiman, T.R., Nam, S.-H. \& Ure, A.L., 2005. Factors affecting conjugated linoleic acid content in milk and meat. Crit. Rev. Food Sci. Nutr. 45, 463-482.

Drackley, J.K., Beaulieu, A.D. \& Elliott, J.P., 2001. Responses of milk fat composition to dietary fat or nonstructural carbohydrates in Holstein and Jersey cows. J. Dairy Sci. 84, 1231-1237.

Ferlay, A., Martin, B., Pradel, P., Coulon, J.B. \& Chilliard, Y., 2006. Influence of grass-based diets on milk fatty acid composition and milk lipolytic system in Tarentaise and Montbéliarde cow breeds. J. Dairy Sci. 89, 4026-4041.

Ferlay, A., Martin, B., Lerch, S., Gobert, M., Pradel, P. \& Chilliard, Y., 2010. Effects of supplementation of maize silage diets with extruded linseed, vitamin $E$ and plant extracts rich in polyphenols, and morning $v$. evening milking on milk fatty acid profiles in Holstein and Montbéliarde cows. Animal 4, 627-640.

German, J., Gibson, R., Krauss, R., Nestel, P., Lamarche, B., Van Staveren, W., Steijns, J., de Groot, L., Lock, A. \& Destaillats, F., 2009. A reappraisal of the impact of dairy foods and milk fat on cardiovascular disease risk. Eur. J. Nutr. 48, 191-203.

Haug, A., Hostmark, A.T. \& Harstad, O.M., 2007. Bovine milk in human nutrition: a review. Lipids Health Dis. $6,25$.

Kelsey, J.A., Corl, B.A., Collier, R.J. \& Bauman, D.E., 2003. The effect of breed, parity, and stage of lactation on conjugated linoleic acid (CLA) in milk fat from dairy cows. J. Dairy Sci. 86, 2588-2597.

Kliem, K.E., Aikman, P.C., Humphries, D.J., Morgan, R., Shingfield, K.J. \& Givens, D.I., 2009. Effect of replacing calcium salts of palm oil distillate with extruded linseeds on milk fatty acid composition in Jersey and Holstein cows. Animal 3, 1754-1762.

Kuczyńska, B., Puppel, K., Metera, E., Kliś, P., Grodzka, A. \& Sakowski, T., 2011. Fatty acid composition of milk from Brown Swiss and Holstein-Friesian black and white cows kept in a certified organic farm. Ann. Warsaw Univ. of Life Sc. - SGGW, Anim. Sci. 49, 61-67.

Kuczyńska, B., Puppel, K., Gołębiewski, M., Kordyasz, M., Grodzki, H. \& Brzozowski, P., 2012. Comparison of fat and protein fractions of milk constituents in Montbéliarde and Polish Holstein-Friesian cows from one farm in Poland. Acta Vet. Brno 81, 139-144.

Lawless, F., Stanton, C., L'Escop, P., Devery, R., Dillon, P. \& Murphy, J.J., 1999. Influence of breed on bovine milk cis-9, trans-11 conjugated linoleic acid content. Livest. Prod. Sci. 62, 43-49.

Lichtenstein, A.H., 2003. Dietary fat and cardiovascular disease risk: quantity or quality? J. Women's Health 12, 109-114.

Lock, A.L. \& Bauman, D.E., 2004. Modifying milk fat composition of dairy cows to enhance fatty acids beneficial to human health. Lipids 39, 1197-1206.

Markiewicz-Kęszycka, M., Czyżak-Runowska, G., Lipińska, P. \& Wójtowski, J., 2013. Fatty acid profile of milk - a review. Bull. Vet. Inst. Pulawy 57, 135-139.

Maurice-van Eijndhoven, M.H.T., Hiemstra, S.J. \& Calus, M.P.L., 2011. Milk fat composition of 4 cattle breeds in the Netherlands. J. Dairy Sci. 94, 1021-1025.

Maurice-van Eijndhoven, M.H.T., Bovenhuis, H., Soyeurt, H. \& Calus, M.P.L., 2013. Differences in milk fat composition predicted by mid-infrared spectrometry among dairy cattle breeds in the Netherlands. J. Dairy Sci. 96, 2570-2582.

Mele, M., Conte, G., Castiglioni, B., Chessa, S., Macciotta, N.P.P., Serra, A., Buccioni, A., Pagnacco, G. \& Secchiari, P., 2007. Stearoyl-coenzyme A desaturase gene polymorphism and milk fatty acid composition in Italian Holsteins. J. Dairy Sci. 90, 4458-4465. 
Mensink, R.P. \& Katan, M.B., 1992. Effect of dietary fatty acids on serum lipids and lipoproteins. A metaanalysis of 27 trials. Arterioscler. Thromb. 12, 911-919.

Mills, S., Ross, R.P., Hill, C., Fitzgerald, G.F. \& Stanton, C., 2011. Milk intelligence: Mining for bioactive substances associated with human health. Int. Dairy J. 21, 377-401.

Moore, C.E., Kay, J.K., Colllier, R.J., VanBaale, M.J. \& Baumgard, L.H., 2005. Effect of supplemental conjugated linoleic acids on heat-stressed Brown Swiss and Holstein cows. J. Dairy Sci. 88, 1732-1740.

Morales, M.S., Palmquist, D.L. \& Weiss, W.P., 2000. Milk fat composition of Holstein and Jersey cows with control or depleted copper status and fed whole soyabeans or tallow. J. Dairy Sci. 83, 2112-2119.

Muchenje, V., Dzama, K., Chimonyo, M., Strydom, P.E., Hugo, A. \& Raats, J.G., 2009. Some biochemical aspects pertaining to beef eating quality and consumer health: A review. Food Chem. 112, 279-289.

Nantapo, C.T.W., Muchenje, V. \& Hugo, A., 2014. Atherogenicity index and health-related fatty acids in different stages of lactation from Friesian, Jersey and Friesian x Jersey cross cow milk under a pasture-based dairy system. Food Chem. 146, 127-133.

Orellana, C., Peña, F., García, A., Perea, J., Martos, J., Domenech, V. \& Acero, R., 2009. Carcass characteristics, fatty acid composition, and meat quality of Criollo Argentino and Braford steers raised on forage in a semi-tropical region of Argentina. Meat Sci. 81, 57-64.

Osterroht, C., 1987. Determination of particulate, fatty acids as p-bromophenacyl- or phenylphenacylesters using HPLC. Chromatographia 23, 419-422.

Palladino, R.A., Buckley, F., Prendiville, R., Murphy, J.J., Callan, J. \& Kenny, D.A., 2010. A comparison between Holstein-Friesian and Jersey dairy cows and their F1 hybrid on milk fatty acid comparison under grazing conditions. J. Dairy Sci. 93, 2176-2184.

Palmquist, D.L., Beaulieu, A.D. \& Barbano, D.M., 1993. Feed and animal factors influencing milk fat composition. J. Dairy Sci. 76, 1753-1771.

Palmquist, D.L., Stelwagen, K. \& Robinson, P.H., 2006. Modifying milk composition to increase use of dairy products in healthy diets - Preface. Anim. Feed Sci. Technol. 131, 149-153.

Parodi, P., 2009. Has the association between saturated fatty acids, serum cholesterol and coronary heart disease been over emphasized? Int. Dairy J. 19, 345-361.

Pešek, M., Špička, J. \& Samková, E., 2005. Comparison of fatty acid composition in milk fat of Czech Pied cattle and Holstein cattle. Czech J. Anim. Sci. 50, 122-128.

Poulsen, N.A., Gustavsson, F., Glantz, M., Paulsson, M., Larsen, L.B. \& Larsen, M.K., 2012. The influence of feed and herd on fatty acid composition in 3 dairy breeds (Danish Holstein, Danish Jersey, and Swedish Red). J. Dairy Sci. 95, 6362-6371.

Reh, W.A., Maga, E.A., Collette, N.M.B., Moyer, A., Conrad-Brink, J.S., Taylor, S.J., DePeters, E.J., Oppenheim, S., Rowe, J.D., BonDurant, R.H., Anderson, G.B. \& Murray, J.D., 2004. Using a stearoylCoA desaturase transgene to alter milk fatty acid composition. J. Dairy Sci. 87, 3510-3514.

Samková, E., Spicka, J., Pesek, M., Pelikanova, T. \& Hanus, O., 2012. Animal factors affecting fatty acid composition of cow fat: A review. S. Afr. J. Anim. Sci. 42, 83-100.

Schennink, A., Heck, J.M.L., Bovenhuis, H., Visker, M.H.P.W., Van Valenberg, H.J.F. \& Van Arendonk, J.A.M., 2008. Milk fatty acid unsaturation: Genetic parameters and effects of stearoyl-CoA desaturase (SCD1) and acyl CoA: diacylglycerol acyltransferase 1 (DGAT1). J. Dairy Sci. 91, 2135-2143.

Simopoulos, A.P., 2002. The importance of the ratio of omega-6/omega-3 essential fatty acids. Biomed. Pharmacother. 56, 365-379.

Soyeurt, H., Dardenne, P., Gillon, A., Croquet, C., Vanderick, S., Mayeres, P., Bertozzi, C. \& Gengler, N., 2006. Variation in fatty acid contents of milk and milk fat within and across breeds. J. Dairy Sci. 89, 4858-4865.

Soyeurt, H., Dehareng, F., Mayeres, P., Bertozzi, C. \& Gengler, N., 2008. Variation of $\Delta 9$-desaturase activity in dairy cattle. J. Dairy Sci. 91, 3211-3224.

Stoop, W.M., Van Arendonk, J.A.M., Heck, J.M.L., Van Valenberg, H.J.F. \& Bovenhuis, H., 2008. Genetic parameters for major milk fatty acids and milk production traits of Dutch Holstein-Friesians. J. Dairy Sci. 91, 385-394.

Ulbricht, T.L.V. \& Southgate, D.A.T., 1991. Coronary heart disease: seven dietary factors. Lancet 338, 985-992.

White, S.L., Bertrand, J.A., Wade, M.R., Washburn, S.P., Green Jr., J.T. \& Jenkins, T.C., 2001. Comparison of fatty acid content of milk from Jersey and Holstein cows consuming pasture or total mixed ration. J. Dairy Sci. 84, 2295-2301.

Williams, C.M., 2000. Dietary fatty acids and human health. Annales De Zootechnie 49, 165-180. 